\title{
La justicia transicional en Colombia en el siglo XXI*
}

\section{Transitional justice in Colombia in the 21st century}

\author{
Román Francisco Téllez Navarro ${ }^{1 凶} \underline{\mathrm{ORCID}}$, Luz Adriana Díaz Orozco ${ }^{2 凶}$, Brayan Alexis Chaux \\ $\operatorname{Vargas}^{3 凶}$, Andrea Gómez Piedrahita ${ }^{4 凶}$, María Fernanda Cárdenas Hernández 4 ॠ
}

\begin{abstract}
"Artículo producto del proyecto titulado "Las medidas de no repetición en las decisiones de los órganos de protección de Derechos Humanos en los países latinoamericanos que han tenido Comisiones de la Verdad", rubricado INV-DER-3156, desarrollado al interior de la línea "Derecho Internacional, Derechos Humanos, Derecho Internacional Humanitario", correspondiente al grupo de "Derecho Público" del Centro de Investigaciones Jurídicas, Políticas y Sociales de la Facultad de Derecho de la Universidad Militar Nueva Granada. Proyecto financiado por la Vicerrectoría de Investigaciones de la Universidad Militar Nueva Granada - Vigencia 2020.

${ }^{1}$ Docente de la Universidad Militar Nueva Granada, Bogotá, Colombia. Investigador del grupo de "Derecho Público" y de la línea de investigación "Derecho Internacional, Derechos Humanos y Derecho Internacional Humanitario "del Centro de Investigaciones Jurídicas, Políticas y Sociales de la Facultad de Derecho de la Universidad Militar Nueva Granada. Abogado de la Universidad Libre de Colombia. Especialista en Derecho Constitucional de la Universidad Libre de Colombia. Magíster en Derecho Procesal Penal de la Universidad Militar Nueva Granada.

${ }^{2}$ Auxiliar de Investigación del Proyecto INV-DER-3156. Estudiante de la Facultad de Derecho de la Universidad Militar Nueva Granada, Bogotá, Colombia. Integrante del Semillero de Derechos Humanos y Litigio Interamericano.

${ }^{3}$ Auxiliar de Investigación del Proyecto INV-DER-3156. Estudiante de la Universidad Militar Nueva Granada, Bogotá, Colombia. Facultad Derecho, IX Semestre.

${ }^{4}$ Auxiliar de Investigación del Proyecto INV-DER-3156. Estudiante de la Universidad Militar Nueva Granada, Bogotá, Colombia. Facultad Derecho, Integrante del Semillero de Derechos Humanos y Litigio Interamericano, IX Semestre.
\end{abstract}

Fecha correspondencia:

Recibido: octubre 04 de 2021.

Revisado: noviembre 01 de 2021.

Aceptado: noviembre 12 de 2021.

Forma de citar:

Tellez, Román Francisco; Díaz, Luz Adriana; Chaux, Brayan Alexis; Gómez, Andrea y Cárdenas, María Fernanda. "La justicia transicional en Colombia en el siglo XXI". En: Revista CES Derecho. Vol. 12, No. 2, julio a diciembre de 2021, p. 162-189.

https://dx.doi.org/10.21615/ cesder.6426

\section{Resumen}

El artículo, aborda la manera en que diferentes gobiernos, realizaron procesos de justicia transicional en el siglo XXI. De acuerdo con lo anterior, el escrito describe cómo, en este siglo, se realizaron dos procesos con estas características. El primero corresponde al desarrollado en la administración del expresidente Álvaro Uribe Vélez, mediante la expedición de la Ley 975 de 2005 y el segundo el ejecutado por el expresidente Juan Manual Santos Calderón y conocido como el Acuerdo de Paz. El lector encontrará en el presente artículo la descripción de cómo se originaron cada uno de estos procesos, así como también los organismos creados o adaptados para lograr el sometimiento a la civilidad de aquellos integrantes de los grupos paramilitares y guerrilleros, encontrar los responsables 
Open access

(C) Derecho de autor

Licencia creative commons

Ética de publicaciones

Revisión por pares

Gestión por Open Journal

System

DOI: 10.21615/cesder.6426

ISSNe 2145-7719

Publica con nosotros

y establecer las respectivas sanciones. Finalmente se establecerán algunas diferencias importantes entre los dos procesos, que los hace únicos.

Palabras claves: justicia transicional; procesos de paz; comisiones de la verdad.

\section{Abstract}

This article shows the way in which different governments carried out transitional justice processes in the 21st century. In accordance with the above, the document describes how, in this century, two processes with these characteristics were carried out. The first corresponds to the one carried out under the government of former President Álvaro Uribe Vélez, through the issuance of Law 975 of 2005 and the second the one executed by former President Juan Manual Santos Calderón and known as the Peace Agreement. The reader will find in this article the description of how each of these processes originated, as well as the organisms created or adapted to achieve submission to civil life, of the members of the groups outside the law, find those responsible and establish the respective sanctions. Finally, some important differences between the two processes will be established, which makes them unique.

Keywords: transitional justice; peace processes; truth commissions.

\section{Introducción}

La historia republicana de Colombia ha caracterizado por un común denominador, la violencia. No en vano Acosta (2005) señala que el conflicto tiene "...raíces que provienen del nacimiento mismo de la Nación y de su proyección política hacia la construcción de un modelo estatal, luego de lograda su independencia de la corona española". (Pág. 19). Por lo anterior, no es temerario afirmar que la nación colombiana ha nacido, crecido y se ha desarrollado acompañada de las guerras y del dolor que estas producen.

Si bien lo señalado con anticipación corresponde a una realidad, 1948 y la muerte del caudillo liberal, Jorge Eliecer Gaitán, generó un caos social, recrudecido por la guerra entre militantes del partido liberal y del partido conservador. La represión estatal, producto la de hegemonía conservadora, la persecución y muerte de diferentes líderes liberales promovieron que, en 
algunos sectores del territorio nacional, los liberales empezaran “...a proponer la formación de guerrillas y afines de 1949 comenzaron a actuar grupos armados en los Llanos, Antioquia y el Tolima. (Melo, 2017, Pág. 216)".

En las décadas posteriores, los movimientos insurgentes tomaron fuerza, y prácticamente se encontraban apostados a lo largo y ancho del país. Paralelamente las luchas por el poder, entre los partidos tradicionales continuaban, permitiendo que los grupos insurgentes fueran tomando el control de ciertas regiones y, por otra parte, que el General Rojas Pinilla tomara el poder quien, entre otras promesas, en búsqueda del favor del pueblo, procuró erradicar la violencia. Promesa que no pudo cumplir, pues como lo señala Bushnell (2008) “...hubo un núcleo pertinaz de guerrilleros que no aceptó la amnistía de Rojas Pinilla. (Pág. 313). Lo anterior, como lo indica el citado autor, no espero la respuesta oficial por parte del presidente que no fue otra que "una campaña de represión militar contra algunas de las plazas fuertes de la guerrilla" (Pág. 313).

Los múltiples intentos, provenientes de diferentes gobiernos, con el fin de generar espacios para que los integrantes de los grupos insurgentes volvieran a la vida civil, lograron que grupos guerrilleros, entre ellos el M-19, el EPL, el PRT y el Quintín Lame, se acogieron a las políticas de desmovilización del siglo XX. Lo anterior trajo consigo dos fenómenos paralelos, por un lado, el fortalecimiento de los grupos guerrilleros no desmovilizados como las FARC - EP y el ELN y por el otro el nacimiento de un grupo armado paramilitar de ultraderecha conocido como las AUC, como respuesta a este fortalecimiento.

Las guerras internas entre los grupos subversivos y paramilitares, paramilitares que últimos en algunas ocasiones actuaron con anuencia de agentes estatales, tal como lo dejó en evidencia la Corte Interamericana de Derechos Humanos en diferentes sentencias, junto con el patrocinio del narcotráfico, desataron una ola de violencia que el país no había experimentado. Las masacres, el desplazamiento forzado, los homicidios selectivos de distintos líderes políticos y hasta el genocidio, fueron el pan de cada terminando el siglo XX e iniciando el XXI.

Colombia, buscando una salida a esta crisis y para frenar esta violencia desmedida, decidió modificar la Constitución de 1886, estableciendo como pilares fundantes de la nueva Carta Política, un Estado Social de Derecho, edificado en el respeto por la dignidad de todas las personas, elevando la paz a una meta estatal, desde el preámbulo mismo y a un derecho fundamental. Lo anterior, exige a los gobiernos la creación de políticas que garanticen la materialización de esta meta y a su vez protección de este derecho fundamental. 
Es por lo anterior que, en el siglo XXI, se desarrollaron dos procesos de justicia transicional de gran importancia para el país. El primero adelantado a través de la Ley 975 de 2005, por medio de la cual se logró desmovilizar una gran cantidad de paramilitares de las AUC y de algunos miembros de grupos guerrilleros y el segundo, la desintegración del grupo insurgente de las FARC-EP, mediante el Acuerdo de Paz suscrito en el año 2016.

Conocer las etapas de formación de estos procesos, el desarrollo de los mismos y las diferencias sustanciales, son elementos preponderantes para la materialización de los objetivos de los procesos de Justicia Transicional, enmarcados en la búsqueda de la Justicia, la verdad, la reparación y la no repetición.

\section{La Justicia Transicional en el desarrollo de la Ley $\mathbf{9 7 5}$ de $\mathbf{2 0 0 5}$}

La Constitución de 1991 consagró la paz como un derecho de carácter fundamental, sin embargo, desde la promulgación de esta norma superior, el conflicto armado interno ha sido un obstáculo para materializar el mismo. En la historia del conflicto colombiano, se ha demostrado que la justicia transicional, es el mecanismo idóneo para dirimir cualquier diferencia interna, tal como se evidenció en diferentes países del mundo, que tramitaron sus conflictos por medio de este mecanismo. Colombia no ha sido ajena a lo anterior, prueba de ello, fue la promulgación y entrada en vigencia de la Ley 975 del 2005, Ley de Justicia y Paz.

Desde la entrada en vigencia de la Constitución de 1991, se han realizado dos procesos de justicia transicional. El primer proceso, fue el que se conoció como la Ley de Justicia y Paz, expedida en el gobierno de Álvaro Uribe Vélez (2002- 2010), quien "en concordancia con las promesas que impulsó en su campaña, Uribe Vélez inició un proceso de diálogo con las denominadas Autodefensas Unidas de Colombia (en adelante AUC) que converge, luego de muchas complicaciones y controversias, en la Ley 975 de 2005." (Centro Nacional de Memoria Histórica, 2018, pág. 12) y el segundo, y más reciente el Acuerdo de Paz suscrito con el grupo insurgente de las FARC-EP, proceso que será abordado con posterioridad, en el presente artículo.

Frente al primer proceso, se puede considerar que el gobierno del expresidente Álvaro Uribe, fue el primero en impulsar una política de justicia transicional, que inicialmente, "solo estuvo interesado en negociar con los grupos paramilitares a los que desmanteló con la Ley 975 de 2005" (Francisco Barbosa, 2017, pág. 65). No obstante, la ley de Justicia y Paz estableció componentes normativos, cuyos efectos fueron establecer un hito en el ordenamiento jurídico colombiano, como la concepción dogmática de la víctima del conflicto armado, mecanismos 
jurídicos especiales bajo el marco de la justicia transicional, dispositivos especiales para buscar la verdad material, reparación integral a las víctimas del conflicto armado y la desmovilización de los integrantes de las autodefensas y de miembros de otros grupos al margen de la ley.

En esta misma línea, se puede establecer que "La ley 975 de 2005, nació contra legem, esto es, rigiendo hacia el pasado. Es el único caso en la historia de la legislación colombiana, en que una ley que se promulgue y se expide se refiere a hechos ocurridos antes de su vigencia, afectando de manera considerable el principio de no retroactividad de la ley." (Beatriz Cuervo \& otros, 2014)

La descrita ley consagró la verdad, la justicia y la reparación como derechos de las víctimas, permitiendo cumplir los fines y objetivos que se establecen en los procesos de justicia transicional. De igual manera, la "ley 975 de 2005 ha trazado la implementación de un "sistema penal" aplicable a los integrantes de grupos al margen de la ley que decidan desvincularse de su actividad ilícita." (Hernández, 2007). De la misma forma, brindó una serie de derechos que permitieron dirimir el conflicto armado, prueba de ello, el acceso a la defensa técnica, reducción de la pena o una pena alternativa, entre otros.

Por otra parte, con la implementación de la ley de Justicia y Paz, nació la Unidad Nacional de Fiscalía para la Justicia y la Paz, con el propósito de "adelantar las diligencias que por razón de su competencia, le corresponden a la Fiscalía General de la Nación" (Ley 975 de 2005 art 33, 2005). Por su parte, la Defensoría Pública y la Procuraduría Judicial para la Justicia y la Paz, asumieron un rol esencial para materializar el objeto de la mencionada ley.

El trámite de la norma se realizó a través de una ley ordinaria, lo que conllevó a que la misma fuera demandada mediante una acción pública de inconstitucionalidad, ante la Corte Constitucional, por vicios de procedimiento. Sin embargo, a juicio de esta corporación, la ley de Justicia y Paz fue declarada exequible, estableciendo, bajo los criterios de la hermenéutica legal, que la ley no colisionaba con la reserva de la ley estatutaria. Asimismo, este máximo tribunal constitucional mediante la Sentencia C-370 de 2006, consideró que la Ley 975 de 2005, “...es un desarrollo de la Constitución de 1991".

Por otro lado, el desarrollo de la ley de Justicia y Paz, se caracterizó por la implementación de un proceso penal especial cuya finalidad fue la búsqueda de la verdad, la justicia y la reparación integral a las víctimas. De igual manera, satisfacer el derecho fundamental a la paz a la 
ciudadanía colombiana, desmovilizando a los grupos al margen de la ley, a su vez, la reincorporación de sus integrantes a la vida civil.

Este proceso judicial especial de Justicia y Paz, se caracterizó por la participación procesal y activa de las víctimas y en lo referente a los integrantes de los grupos desmovilizados, estos debían cumplir con determinadas formalidades para ser parte en el proceso y obtener los beneficios que la ley les otorgaba.

De manera análoga, la aplicación del proceso penal especial de Justicia y Paz debía estar sujeto a las siguientes formalidades: la desmovilización, la postulación y la elegibilidad. Lo anterior, fue fundamental para dar inicio a los propósitos dogmáticos del desarrollo de la justicia transicional de la ley. Igualmente, la desmovilización se estableció como un principio fundamental, para dar trámite al desarrollo del proceso penal especial implementado en la aludida ley. Llevado a cabo este acto de desmovilización, la postulación conminaba a que los individuos o grupos desmovilizados fueran presentados ante Fiscalía General de la Nación, por parte del Gobierno Nacional, con el propósito de que los sujetos desmovilizados, pudieran ser elegidos para los beneficios procesales y sustanciales que consagró la ley de Justicia y Paz, como por ejemplo, "la pena alternativa que consiste en privación de la libertad por un período mínimo de cinco (5) años y no superior a ocho (8) años”. (Ley 975 de 2006 art 29, 2005)

De la aplicación de los factores anteriores, se derivó la elegibilidad para gozar de los beneficios que otorgaba la política de Justicia y Paz, para lo cual la Ley 975 del 2005, estableció los siguientes requisitos, para aquellos sujetos que quisieran desmovilizarse de forma colectiva:

"Primero, consagró que el grupo armado organizado, se hubiese desmovilizado y desmantelado, en cumplimiento de un acuerdo con el Gobierno Nacional. Segundo, que se entregarán los bienes producto de las actividades ilegales. Tercero, que el grupo pusiera a disposición del Instituto Colombiano de Bienestar Familiar, la totalidad de menores de edad reclutados. Cuarto, que el grupo cesara toda interferencia al libre ejercicio de los derechos políticos y libertades públicas y cualquier otra actividad ilícita. Quinto, que el grupo no se haya organizado con la finalidad delictivas como el narcotráfico y el enriquecimiento ilícito. Sexto que se liberaran las personas secuestradas, que se hallaran en su poder" (Artículo 10).

Por otra parte, para los individuos que pertenecían a grupos al margen de la ley y se desmovilizaran individualmente, la ley de Justicia y Paz consagró que debían cumplir con los siguientes requisitos “Que entregue información o colabore con el desmantelamiento del grupo 
al que pertenecía. Que haya suscrito un acta de compromiso con el Gobierno Nacional. Que se haya desmovilizado y dejado las armas en los términos establecidos por el Gobierno Nacional para tal efecto. Que cese toda actividad ilícita." (Artículo 11)

Ahora bien, en la implementación de este modelo de justicia, el Gobierno Nacional expidió el Decreto 3391 de 2006, por el cual se reglamentó parcialmente la Ley 975 de 2005, permitiendo que los fiscales delegados, asignados de la Unidad de Justicia y Paz y los magistrados de conocimiento, pudieran "solicitar a la autoridad competente ante la cual se haya surtido la desmovilización que certifique sobre los actos materiales de cumplimiento de los requisitos contemplados en los mencionados artículos 10 y 11 que se hayan presentado con ocasión de la desmovilización de cada grupo armado específico organizado al margen de la ley cuyos miembros hayan sido postulados por el Gobierno Nacional." Lo anterior, con la finalidad de establecer, quiénes de los desmovilizados, en verdad podían acceder a los beneficios contemplados en la ley.

El sistema procesal implementado en la ley de Justicia y Paz, en el marco de los principios filosóficos de la Justicia transicional, estableció un proceso penal diferente cuya "naturaleza especial impide encuadrar el proceso penal diseñado en la Ley 975 de 2005, en un modelo procesal estrictamente acusatorio o inquisitivo." (Cardona, 2011, pág. 88). De esta manera, se buscó hacer efectivo y garantizar socialmente el derecho fundamental a la paz de la población colombiana, así como lograr la verdad, la justicia y la reparación para las víctimas del conflicto.

Dentro de la ejecución de este procedimiento, la diligencia versión libre y la confesión por parte de los agentes desmovilizados, en la aplicación del proceso penal especial de la ley de justicia y paz, daba inicio al proceso. Por ello, estas dos diligencias fueron primordiales para cumplir con los derechos de las víctimas, entre ellos a la verdad y la reparación. De conformidad con el portal web Dejusticia, comenzar con las versiones de los victimarios, permitió que "la verdad sea la base de un proceso de paz duradero y respetuoso de los derechos de las víctimas, pues sin ella no se sabe a quién castigar ni a quién reparar, ni como poner en marcha mecanismos que impidan la recurrencia de las conductas atroces". (Uprimny, 2005)

Posterior a esta etapa, seguía la audiencia de formulación de imputación. Este acto procesal se basó en que la "Fiscalía General de la Nación le comunica al postulado que lo va a investigar por su participación como autor o partícipe de determinados hechos delictivos." (Ministerio de Justicia y del Derecho, 2015, pág. 25). Agotada esta etapa, sigue la que corresponde a la verificación e investigación, por parte de la Fiscalía General de la Nación, en donde el ente 
investigador realizaba "las labores técnicas de verificación y corroboración de la información ofrecida por el postulado en la diligencia de versión libre." (Ministerio de Justicia y del Derecho, 2015, pág. 26)

Concluida la fase anterior, continuaba la audiencia concentrada de formulación y aceptación de cargos. Esta se sustentó con "base en los resultados de la etapa de investigación y verificación, que adelantó previamente la Fiscalía, y ya ante el magistrado de conocimiento (es decir, ya ante el juez que va a presidir el juicio), la Fiscalía formula cargos en contra del postulado procesado." (Ministerio de Justicia y del Derecho, 2015, pág. 32)

Posteriormente se continuaba con el incidente de reparación integral, siendo este "es un espacio de satisfacción en el que las víctimas pueden preguntar a sus victimarios los hechos y las razones de su victimización." (Ministerio de Justicia y del Derecho, 2015, pág. 34). Por último, se emitía la sentencia, que se fundamentaba en que "el magistrado de conocimiento de la Sala de Justicia y Paz del Tribunal respectivo da lectura al fallo en el cual decide sobre la responsabilidad penal del postulado o postulada, individualizando la pena ordinaria, otorgando la pena alternativa y ordenando las medidas de reparación a favor de las víctimas." (Ministerio de Justicia y del Derecho, 2015, pág. 34)

En vista de este modelo de Justicia Transicional, se permitió la reparación de las víctimas del conflicto armado y la reincorporación a la vida civil de los integrantes de grupos armados al margen de la ley, por ejemplo, se logró la desmovilización de un gran número de integrantes de la organización paramilitar denominada las Autodefensas Unidas de Colombia "AUC", integrantes de las FARC-EP y otros grupos guerrilleros. De acuerdo con lo anterior, el gobierno logró que, “...entre los años 2003 y 2006 se desmovilizaron, colectiva e individualmente, 35.317 combatientes paramilitares en el marco de la negociación entre el Gobierno Nacional y las Autodefensas Unidas de Colombia (Auc). De estos, 4.588 paramilitares fueron postulados a la Ley de Justicia y Paz (Ley 975 de 2005)". (Centro Nacional de Memoria Histórica, 2019)

\section{La Justicia Transicional en el Acuerdo de Paz con las Farc-Ep}

En el año 2016, Colombia firmó un acuerdo de paz, con el grupo guerrillero de las FARC-EP, cuyo accionar bélico se prolongó por varias décadas. El estado buscando mitigar y terminar con todos los hechos que por más de 60 años generaron un conflicto violento en el país, estableció como una de sus prioridades, lograr un consenso con el grupo insurgente y obtener su desmovilización. A raíz de lo anterior, fue necesario buscar un camino para la consolidación de una paz que diera tranquilidad a la población colombiana. Terminar un conflicto de tantos años, requirió involucrar un sinnúmero de aspectos, para la correcta implementación de un 
verdadero proceso de paz, así como los consensos necesarios y a los que pudieran llegar cada una de las partes, con la finalidad de plasmar los mismos en un acuerdo y así poder evitar los errores de las negociaciones de paz anteriores. Aunado a lo anterior, fue necesario tener en cuenta que, "las negociaciones de paz en mención surgen en un contexto de polarización de la sociedad civil en torno de las mismas, satanización de la construcción de la paz y significativo escepticismo" (García, 2010 citado por Hernández 2015 Pág. 194).)

La sociedad colombiana no creía en las negociaciones de paz, y no es para menos, con fracasos como los evidenciados en procesos anteriores, que tuvieron como resultado un incremento de las situaciones de violencia, la sensación de poca justicia y de condenas ínfimas, promovían un entendimiento razonable al rechazo y a la negativa frente al proceso de paz con las FARC-EP.

No obstante, es posible evidenciar que este proceso de paz, a diferencia de los otros, inició con aspectos positivos, pucomo lo señala Hernández (2015) estas negociaciones "comenzaron con condiciones muy favorables, dado que las partes en conflicto habían evidenciado las dificultades que ofrecía el intento de solución por vía militar del conflicto armado y el múltiple y costoso impacto de este mecanismo de resolución del mismo" (p, 195) ya que, con antecedentes como la seguridad democrática, donde no se tuvo en cuenta a sectores de opinión tanto de la sociedad como de los propios grupos armados, Colombia entendió, que tratar de erradicar unilateral y militarmente a los grupos insurgentes, no era la vía más eficiente ni eficaz.

Es por ello que, en la última semana de agosto de 2012, el gobierno de Juan Manuel Santos y los delegados de las FARC-EP, informaron a través de diferentes medios de difusión, que darían inicio a un proceso de diálogos de paz, cuyo objetivo sería terminar la confrontación bélica. El primer paso se dio, el 18 de octubre del año 2012, en Oslo Noruega, instalando la mesa de negociación que continuaría desde el 2013, en La Habana Cuba, con el acompañamiento permanente de garantes internacionales y comisiones representativas.

El desarrollo de las negociaciones de paz, se basaron, de acuerdo con Hernández (2015) en aspectos como:

“...el diálogo, escucha activa, confidencialidad, flexibilidad, persuasión, formulación de propuestas y concreción de acuerdos generales y parciales, entre otras. La paulatina apertura del proceso de negociaciones de paz a la participación de la sociedad civil mediante los foros académicos nacionales y regionales, el encuentro de víctimas con las Farc, la integración de los académicos que conforman la mencionada comisión de la verdad histórica sobre el conflicto en referencia, y aceptación de una comisión de género, entre otras. (Pág. 187 y 196)". 
El proceso de creación de este acuerdo final se dio en 3 fases y cada una de ellas se enfocó en puntos específicos, como se puede observar: La fase uno, denominada exploración (agosto de 2010 a agosto de 2012), se basó en establecer las reglas, la agenda y los procedimientos, con el fin de poder realizar las negociaciones, obteniendo como fruto la parte del documento denominado "Acuerdo General para la Terminación del Conflicto y la Construcción de una Paz Estable y Duradera, en el cual se estableció el propósito del proceso, las condiciones y las reglas de funcionamiento. Departamento Administrativo de la Función Pública"

Del desarrollo de la anterior etapa, se tiene como resultado el nacimiento del Acto Legislativo 01 de 2012, que de acuerdo con Salazar (2017), le impuso al Estado "el deber de investigar y sancionar, mediante mecanismos judiciales y extrajudiciales, utilizando dos criterios fundamentales, la priorización y selección, además de ello, autoriza la renuncia de la persecución penal y la suspensión de la ejecución de la pena", pues su enfoque estaría únicamente en los delitos de lesa humanidad, buscando siempre otorgar justicia, reparación, verdad y no repetición, objetivos anhelados por toda la estrategia del Marco Jurídico para la Paz.

Además, consagró las reglas primordiales sobre las cuales se realizarían los diálogos entre los delegados gubernamentales y los integrantes designados por las FARC-EP, en cumplimiento de las metas establecidas en el preámbulo de la Constitución y el artículo 22.

En la fase dos, designada como desarrollo de las conversaciones (octubre de 2012 a agosto de 2016), se buscó incluir la opinión de los ciudadanos, con la finalidad de cumplir algunos de los deseos de la sociedad colombiana, frente a la anhelada paz. Además, se dispuso, en un primer momento, que ellos tuvieran la última palabra respecto del producto final de esas conversaciones. Con el paso del tiempo y el avance sobre los puntos del acuerdo, en 2015, voceros tanto del Congreso como del Gobierno Nacional impulsaron la idea de que el proceso de aprobación del acuerdo, fuese por medio de un plebiscito, por lo tanto, en septiembre del mismo año, se radicó un proyecto de ley estatutaria que buscaba permitirle al Presidente de la República, convocar un plebiscito como mecanismo para que el pueblo refrendara el Acuerdo, el cual fue aprobado por el congreso en diciembre por medio de ley, que el 18 de julio de 2016 y que la Corte Constitucional, encontró que estaba en consonancia con los mandatos constitucionales de la Carta.

Luego de esta etapa, el 24 de agosto de 2016, se logró el consenso entre el equipo negociador de las dos partes y surgió el acuerdo definitivo y al mismo tiempo, fue sancionada la Ley Estatutaria 1806 de 2016, por medio de la cual se reguló “...el plebiscito para la refrendación del Acuerdo Final para la terminación del conflicto y la construcción de una paz estable y duradera". Cuatro días después se expidió el Decreto 1391, "por medio del cual se convoca a 
un plebiscito", para que así, el 2 de octubre de del mismo año, se pronunciara de manera positiva o negativa sobre el acuerdo, surgiendo a la vez, campañas en todo el país a favor o en contra del mismo.

El 2 de octubre se realizó el tan esperado plebiscito, en el cual participaron, de acuerdo con la Registraduría General de la Nación, 12.808 .858 ciudadanos, de los cuales 6.377 .482 votaron en favor del sí y 6.431.376 mostraron su desacuerdo con lo preguntado en el mecanismo de participación ciudadana. Ante el ajustado resultado, el Gobierno Nacional, decidió convocar un proceso de diálogo, con el fin de ajustar el Acuerdo a los desacuerdos planteados por los precursores del no.

Ante el resultado de las votaciones, se realizaron más de sesenta reuniones con diferentes grupos sociales que hicieron campaña por el no, así como con aquellos que estaban a favor del sí, para que, entre el 20 y el 28 de octubre de 2016, se sostuviera una reunión con la delegación de la FARC-EP y los jefes de la Delegación del Gobierno como del Alto Comisionado, para el examen e incorporación de las propuestas originadas de las anteriores discusiones, para que así, el 12 de noviembre se anuncia que se habían logrado alcanzar un nuevo Acuerdo Final.

Por último, se desarrolló la fase tres, conocida como construcción de paz. Esta fase buscó la construcción de una paz duradera para todos los colombianos y se dio posterior a la firma del Acuerdo Final dándole un enfoque de paz territorial a través del Decreto Ley 885 de 2017, "Por medio del cual se modifica la Ley 434 de 1998 y se crea el Consejo Nacional de Paz, Reconciliación y Convivencia".

Ahora bien, con la firma de este acuerdo de paz, y con la finalidad de alcanzar los objetivos propuestos en el mismo se creó el del Sistema Integral de Verdad, Justicia, Reparación y no Repetición por sus siglas SIVJRNR, integrado según el portal web de la JEP por: "(i) la Comisión para el Esclarecimiento de la Verdad, la Convivencia y la No Repetición; (ii) la Unidad de Búsqueda para Personas dadas por Desaparecidas; (iii) la Jurisdicción Especial para la Paz; (iv) las medidas de reparación integral para la construcción de paz y las garantías de no repetición. Es importante señalar que mediante el Acto Legislativo 01 de 2017 y el Decreto 588 de 2017, nació la Comisión para el Esclarecimiento de la Verdad, la Convivencia y la No Repetición, como un mecanismo de carácter temporal y extrajudicial del SIVJRNR. Su duración está reglada por el artículo primero del Decreto 588 de 2017 y esta será por un período de tres años y cuenta con un período adicional de seis meses. Al ser un mecanismo extrajudicial, de acuerdo al artículo cuarto del mencionado decreto, las actividades realizadas por esta no tendrán carácter judicial, además de ello, la información que reciba o produzca la Comisión, no podrá ser utilizada con el fin de atribuir responsabilidades en procesos judiciales ni podrán requerirla y mucho menos tendrán algún tipo de valor probatorio. 
Por otro lado, la JEP por medio de la Ley Estatutaria 1957 de 2019, fue integrada al ordenamiento jurídico colombiano, estableciendo como función principal, "administrar justicia transicional y así mismo conocer acerca de los delitos realizados dentro del conflicto armado, siempre y cuando hayan sido cometidos antes del primero de diciembre de 2016" (artículo 8). Su objetivo principal, de acuerdo con el artículo 9 es "satisfacer el derecho de las víctimas a la justicia; ofrecer verdad a la sociedad colombiana; proteger los derechos de las víctimas; contribuir al logro de una paz estable y duradera; y adoptar decisiones que otorguen plena seguridad jurídica a quienes participaron de manera directa o indirecta en el conflicto armado interno mediante la comisión de las mencionadas conductas." Además, fu enfoque se encuentra en los delitos más graves y representativos, y su duración no podrá superar los 20 años.

Así las cosas y de conformidad con el al artículo 72 de la Ley 1957 de 2019, la JEP Está integrada por, “a. La Sala de reconocimiento de verdad, de responsabilidad y de determinación de los hechos y conductas. b. El Tribunal para la Paz. c. La Sala de Amnistía o indulto. d. La Sala de definición de situaciones jurídicas, para los casos diferentes a los literales anteriores o en otros supuestos no previstos. e. La Unidad de Investigación y Acusación, la cual debe satisfacer el derecho de las víctimas a la justicia cuando no haya reconocimiento colectivo o individual de Responsabilidad."

Los procesos de la entidad se encuentran estructurados en el artículo 73, en el cual menciona que se aplicarán dos procedimientos: “1. El Procedimiento en caso de reconocimiento de verdad y reconocimiento de responsabilidad, y 2. el Procedimiento en caso de ausencia de reconocimiento de verdad y de responsabilidad". Procesos que inician a partir de los informes de las víctimas y organizaciones estatales y no estatales que sirven como denuncia la JEP, comenzando los trámites de acuerdo a la priorización de cada uno.

Teniendo en cuenta lo anterior, se estableció mediante la Ley 1922 de 2018 que el procedimiento será el siguiente: las indagaciones serán iniciadas por la Unidad de Investigación y Acusación, de acuerdo con las remisiones realizadas por la Sala de Reconocimiento de Verdad y Responsabilidad o la Sección de Revisión del Tribunal. Así mismo se podrán iniciar por requerimiento de la Sala de Definición de Situaciones Jurídicas y de la Sala de Amnistías e Indultos. Es una etapa con una duración máxima de doce meses, prorrogables por otros seis. Vencido el término, el Fiscal podrá presentar el escrito de acusación ante la Sección de Primera Instancia para Casos de Ausencia de Reconocimiento de Verdad y Responsabilidad, o solicitar la preclusión de la investigación ante la Sala de Definición de Situaciones Jurídicas.

Una vez llegados a este punto, se inicia la etapa de versiones voluntarias, conforme lo establecido en la Ley 1922 de 2018, en la cual, de acuerdo con el artículo 27 A, "La aceptación de la autoría o participación por parte del compareciente en la versión, tendrá el valor de una 
confesión". Dicha diligencia se practicará, "en presencia del compareciente y su defensor". Esta versión tiene como propósito el almacenamiento de información, para contribuir a la búsqueda de la verdad. Para tener certeza de si la conducta existió, que grado de responsabilidad se le puede endilgar y además identificar que este tipo de conductas no correspondan aquella que no pueden se amnistiables.

La citada ley señala en el artículo 28 que "Recibida la resolución de conclusiones, la Sección de Reconocimiento de Verdad y Responsabilidad del Tribunal, realizará el reparto del caso a uno de los Magistrados de la Sección, quien actuará como ponente. El Magistrado Ponente, mediante resolución que será emitida dentro de los tres días siguientes al reparto, comunicará a la Sala de Reconocimiento de verdad y Responsabilidad, como también a los sujetos procesales y a los intervinientes, que la Sección asume competencia". Posteriormente el Magistrado competente "dentro de los 30 días siguientes, efectuará el estudio preliminar de la resolución de conclusiones y sus anexos. Vencido este término, presentará a la Sección su informe preliminar, donde se discutirá el enfoque y si es necesario se orientará el estudio, en un término máximo de noventa días para presentación de la ponencia." (artículo 29).

La ponencia será estudiada y, dentro de la misma se "determinará la correspondencia entre hechos, conductas reconocidas, calificaciones realizadas, pruebas allegadas, responsables, y las propuestas de la sanción, y sobre todo examinar las condiciones en las cuales se contribuye a la verdad y reparación integral. Y esta decisión adoptada por la Sección admitirá recurso de reposición. Posterior a ello, en la audiencia de verificación la Sección verificará el cumplimiento de las condiciones de contribución a la verdad y la forma de reparación en el marco del SIVJRNR." (artículo 30)

Una vez surtido todo lo anterior, la ley establece que el despacho deberá proferir la respectiva sentencia, "fijando las condiciones y modalidades de la sanción" (artículo 30). En todo caso, el proceso y por ende la sentencia tendrá como finalidad principal el reconocimiento de la verdad, el aporte de los victimarios a la misma, el grado de responsabilidad y la correspondencia con los hechos, entre otros aspectos. De no lograrse lo anterior, la Sección dispondrá "la ruptura de la unidad procesal y el envío de la actuación a la UIA" (artículo 32).

\section{Diferencias entre la Ley $\mathbf{9 7 5}$ de $\mathbf{2 0 0 5}$ y el Acuerdo de Paz de 2016}

Colombia en el siglo XXI ha tenido dos procesos de paz. El primero es el proceso de desmovilización para grupos al margen de la ley, promovido por la Ley de Justicia y Paz, establecido en la Ley 975 de 2005 y el segundo Acuerdo de Paz suscrito el 24 de noviembre de 2016 en Bogotá, de los cuales se desprenden importantes diferencias. 
La primera diferencia que se puede encontrar, corresponde al nacimiento de cada proceso. Por una parte, la Ley 975 de 2005 o Ley de Justicia y Paz, fue una norma promovida por el Gobierno Nacional en cabeza del entonces presidente Álvaro Uribe Vélez, tramitada por el Congreso, promulgada el 25 de julio de 2005 y reglamentada mediante 12 decretos. Adicionalmente, se sitúa como la primera ley colombiana, en materia de justicia transicional, que trae consigo el procesamiento, la sanción y las rutas de atención a desmovilizados de grupos al margen de la ley, como también la reparación integral y resarcimiento de los daños causados a sus víctimas.

Teniendo en cuenta su naturaleza jurídica, la Ley 975 de 2005 fue susceptible de un trámite estructurado ante el legislativo, iniciando con la radicación del proyecto de ley, discutido tanto en la Cámara de Representante, como en el Senado de la República y finalizando con la respectiva sanción presidencial. No obstante, tras múltiples proyectos de ley y modificaciones, finalmente se sancionó un texto consolidado, en donde el legislador veló por la garantía de su articulado, conforme a la justicia, verdad y reparación, permitiendo desarrollar y avanzar de forma decidida hacia la reconciliación nacional.

Ahora bien, la Ley 975 de 2005, según Ocampo y Marín (2015) "Tiene su origen en la obligación de acordar un ordenamiento jurídico complementario (Pág.54)". Lo cual, le permitía a esta disposición legal, que los encontrados responsables, por transgredir los preceptos legales, así como también los partícipes de las conductas punibles, fueran investigados y sancionados conforme a los estándares internacionales de la justicia transicional.

Por otro lado, y en lo que concerniente a la creación del Acuerdo de Paz, este fue producto de una negociación previa, entre el Gobierno Nacional y el grupo guerrillero de las FARC-EP, que tras cuatro años de diálogo, se concretó con la firma del mismo en el año 2016.

Inicialmente, para la refrendación de este Acuerdo, se realizó un plebiscito que fue convocado para el 2 de octubre de 2016. Este fue un mecanismo de refrendación, promovido por el presidente de la República mediante Decreto 1391 de agosto de 2016, por medio del cual, convocó a los colombianos para la aprobación o no del acuerdo final, entre el grupo insurgente de las FARC-EP y el Gobierno Nacional, teniendo como resultado el dominio del "No" por un pequeño margen de un poco más de 50.000 votos.

Pese al resultado, el Gobierno Nacional reorientó lo pactado en el Acuerdo de Paz inicial, buscando para la materialización jurídica del acuerdo, un nuevo pacto en el país, que tuvo que ser sometido a un trámite por vía Congreso de la República, que daría como resultado el Acto 
legislativo 01 de 2016. Este Acto Legislativo, le permitió de manera transitoria y excepcional al Congreso de la República, mediante procedimiento especial legislativo, tramitar todos los proyectos de ley necesarios para la consolidación del acuerdo, así como también, le permitió al Gobierno Nacional, para este mismo propósito, proferir los actos administrativos necesarios.

La segunda diferencia que se puede encontrar, corresponde al procedimiento y a los órganos creados para materializar los procesos. En primer lugar, según el Ministerio y Justicia del Derecho la aplicación de la Ley 975 de 2005 “(...) ha sido, especialmente, aplicada a los integrantes de las denominadas Autodefensas Unidas de Colombia (AUC), aunque algunos excombatientes guerrilleros, desmovilizados individuales, también se han postulado a ella". (Ministerio de Justicia y del Derecho, 2015, p. 10), no obstante, lo anterior, con posterioridad, se permitió la incorporación en el programa de todas aquellas personas que hacían parte de los grupos al margen de la ley.

Para el inicio del procedimiento, la ley estableció la necesidad de que los miembros de los grupos armados ilegales, se desmovilizaran. Este fue un proceso penal especial por medio del cual, una vez desmovilizados los ex-combatientes, el Gobierno Nacional procedió con la postulación de los exintegrantes de estos grupos a los procedimientos y beneficios de esta disposición legal, verificando que se cumplieran todos y cada uno los requisitos de elegibilidad contemplados en la ley de justicia y paz, teniendo en cuenta la situación y circunstancias específicas de cada posible beneficiario ya que, se podía estar ante un proceso de desmovilización individual o colectivo. Posteriormente, se daba inicio al proceso judicial de Justicia y Paz, que tenía como objetivo investigar, juzgar y sancionar las conductas delictivas cometidas durante el tiempo en que fueron miembros de las armadas ilegales, cualquiera que fuera.

Para lograr este cometido, se crearon órganos especiales, como la UJP (Unidad de Justicia y Paz) perteneciente a la Fiscalía General de la Nación y facultada por la Ley 975 de 2005 para ser el primer órgano en conocer a él o los nombres de los desmovilizados. Así mismo, a esta unidad le correspondió investigar "las circunstancias de tiempo, modo y lugar en que se realizaron las conductas punibles, las condiciones de vida, sociales, familiares, individuales del imputado y su conducta anterior, los antecedentes judiciales y de policía y los daños que individual o colectivamente haya causado de manera directa a las víctimas..." (art. 15, Ley 975).

Como se indicó en el presente artículo, el proceso “inicia con la diligencia de versión libre y continúa con las audiencias de formulación de imputación, formulación y aceptación de cargos, 
de control de legalidad y de incidente de reparación integral" (Germán Darío Valencia Agudelo, Carlos Alberto Mejía Walker 2010, pág. 7). Surtidas las etapas procesales y para proseguir con el proceso de resocialización, los desmovilizados debían realizar la aceptación pública de los hechos y solicitar perdón público, a las víctimas afectadas por la violencia, para garantizar la no repetición de los hechos victimizantes.

En el procedimiento establecido, cobró gran relevancia los aportes a la verdad de los desmovilizado, pues si en la audiencia el imputado no aceptaba los cargos, o se retractaba de lo dicho en la versión libre, la Fiscalía para la Justicia y la Paz presentaría dicha actuación al funcionario correspondiente, quien realizará la investigación de acuerdo con la ley vigente, al momento de la comisión de las conductas. Estas etapas procesales se surtieron para garantizar y tramitar las respectivas penas e igualmente para evitar que se estuviera frente a un escenario de justificación para los victimarios, en donde pudieran exonerar su responsabilidad. Lo que se buscaba con estos actos, es que los procesados manifestaran su arrepentimiento, pidieran perdón y se hicieran acreedores de los beneficios establecidos entre otros, las penas alternativas.

Frente al Acuerdo de Paz, es necesario indicar que a diferencia del proceso del 2005, se propone un Sistema Integral de Verdad, Justicia, Reparación y no Repetición, que se denomina Jurisdicción Especial para la Paz (JEP). Según la página oficial de la JEP, se define como un "Sistema Integral de Verdad, Justicia, Reparación y no Repetición, (...) tiene la función de administrar justicia transicional y conocer de los delitos cometidos en el marco del conflicto armado que se hubieran cometido antes del 1 de diciembre de 2016" (Jurisdicción Especial para la Paz, 2018, Pág. 1).

La Jurisdicción Especial para la Paz, como su nombre lo indica, es una jurisdicción especial que ejerce funciones judiciales de manera preferente, autónoma y temporal respecto a las conductas cometidas durante el conflicto armado.

Frente al procedimiento, es importante tener en cuenta que entre el Gobierno Nacional y las FARC - EP, determinaron un Sistema Integral integrado, que según el Gobierno Nacional estaría conformado por la "Jurisdicción Especial para la Paz, la Comisión para el Esclarecimiento de la Verdad, la Convivencia y la no Repetición, la Unidad para la Búsqueda de Personas dadas por Desaparecidas en el contexto y en razón del conflicto armado y las medidas de reparación integral para la construcción de paz y las garantías de no repetición" (Acuerdo 1, 2016, punto 5), órganos especiales e independientes a los ordinarios. 
Un tercer aspecto a tener en cuenta como diferencia notable, corresponde a la búsqueda de la verdad. La Ley 975 de 2005 y con ocasión del conflicto existente en el país, tenía como fin genérico dictar "disposiciones para la reincorporación de miembros de grupos armados organizados al margen de la ley, para contribuir de manera efectiva a la consecución de la paz nacional (...)" (Gómez, 2007, p.73). La citada ley reconoció el derecho a la verdad como se constata en su artículo 7, al señalar que: "La sociedad, y en especial las víctimas, tienen el Derecho inalienable, pleno y efectivo de conocer la verdad sobre los delitos cometidos por grupos armados organizados al margen de la ley, y sobre el paradero de las víctimas de secuestro y desaparición forzada."

En este proceso fue evidente la participación de los victimarios, pues en estos procesos se les otorgó la oportunidad de participar en el mismo, protegiendo el derecho a la verdad de los hechos acaecidos a las víctimas, realizando actos de confrontación, relatar los padecimientos que sufrieron las víctimas e incluso, escuchar las narraciones de los detalles aterradores, sobre las causas en las que se dieron los hechos violentos.

En el año 2011, de acuerdo con Centro Nacional de Memoria Histórica, como resultado del acuerdo entre el Gobierno, algunos sectores de la sociedad colombiana y grupos influyentes de la política colombiana se promulgó la Ley 1448 del mismo año, con el fin de “...establecer un conjunto de medidas judiciales, administrativas, sociales y económicas, individuales y colectivas, en beneficio de las víctimas" (artículo 1). Su adopción, según el Centro Nacional de Memoria Histórica, respondió a diversas causas tales como, la influencia extranjera, las constantes indemnizaciones pagadas por el Estado producto de las demandas instauradas en su contra, así como el sacrificio humando de niños, niñas y adolescentes por cuenta de la violencia.

Una de las finalidades de la Ley 1448 de 2011, es indemnizar a las víctimas del conflicto armado por medio de la vía administrativa, siendo este uno de los grandes avances que proyecta la citada ley, así mismo, encuentra relevancia en ser la primera ley que reconoce el conflicto armado interno en Colombia, además de establecer que el Estado debe hacerse responsable de brindarles las herramientas necesarias para reconstruir su programa de supervivencia. (Lefkaditis \& Ordoñez, 2014). Como grandes avances introducidos en el ordenamiento jurídico colombiano, también resulta relevante señalar, como lo establece Silva en el año 2013 que, al reconocer la existencia de un conflicto armado, por parte del Estado, se ratifica la aplicación del 
Derecho Internacional Humanitario, es decir, se permite el cumplimiento de los convenios de Ginebra y los estatutos del tribunal de la Haya junto con la implementación de normas y estatutos internacionales.

Frente a las víctimas se introdujo un cambio sustancial, en comparación con la Ley 975 de 2005, debido a que la ley de víctimas, adopta la definición establecida por las Naciones Unidas, la cual contempla que, "es víctima quien haya padecido daños directos, que provoquen alguna discapacidad, física, mental, entre otras, el sufrimiento emocional, pérdida financiera o menoscabo de sus derechos". No obstante, se reconoce en la misma, no solo a civiles, sino también a los miembros de la fuerza pública que se encuentren en la condición de víctimas.

Pese a los avances registrados, solo seis años después, con la entrada en vigencia de la Ley 1448 de 2011, se documentan aspectos negativos conforme a circunstancias de fondo, tales como, sus efectos de temporalidad, toda vez que las víctimas de actos como consecuencia de un conflicto armado, que tuvo lugar antes o después de la presente ley, no son objeto de protección conforme lo señalado en el artículo 3 de la citada norma. Bajo esta particularidad, se consagra que se protege a toda persona considerada víctima de actos resultado del conflicto armado, que se sitúan temporalmente a partir del año 1985.

De acuerdo a lo establecido, no serían sujeto de protección de esta ley las víctimas de años que anteceden a 1985, es así como no se reconoce que Colombia es un país que ha padecido situaciones violentas, que desencadenaron masacres desde la década de los años 40's y anteriores y cuyas víctimas de desplazamiento forzado, solo tendrían derecho a "una reparación simbólica, no de la restitución de tierras ni de una compensación económica". (Silva, 2013).

De lo anterior también es preciso acotar, que existen más categorizaciones que repercuten en el reconocimiento de derechos en razón a la fecha de su vulneración. Teniendo en cuenta lo anterior la organización de Derechos Humanos Amnistía Internacional en su informe, señaló que con referencia a las acciones de compensación a las víctimas se pueden establecer tres niveles. Como nivel tres aquellas víctimas anteriores a 1985, en el nivel dos se encuentran los afectados de las vulneración de los Derechos Humanos, entre los años de 1985 y 1991, respecto de las cuales no hay lugar a una restitución de tierras sino solo lugar a una indemnización de carácter pecuniaria y finalmente en el nivel uno y de quienes se colige, ostentan mayor protección, se encuentran aquellas que perdieron sus tierras por motivo de ocupación ilegal, 
mediante la violación de sus Derechos Humanos en un periodo que comprende del año 1991 hasta el año en que entró en vigencia la ley, estas víctimas tendrán derecho a la restitución de sus tierras. (Silva, 2013).

Así mismo, respecto de los grupos armados ilegales, como se presumen desmovilizados, consecuencia de la implementación de la Ley 975 de 2005 o ley de justicia y paz, para el Estado colombiano, los grupos delincuenciales existentes, responden a bandas criminales y no a grupos residuales de los procesos de desmovilización, desconociéndose que son organizaciones cuya finalidad criminal es el desplazamiento, la privación ilegal y violenta de la tierra y la realización de todo tipo de vejámenes con la intención de ejercer un control e intimidar a la población, en especial a las Organizaciones Defensoras de los Derechos Humanos, por ende, sus víctimas no son objeto de salvaguarda de la Ley 1448 de 2011. No obstante, en los últimos años se han podido identificar grupos al margen de la ley, cuya conformación en muchos casos cuenta con desmovilizados, contradiciendo las versiones oficiales.

Múltiples organizaciones internacionales de Derechos Humanos denuncian que, en Colombia, pese a los avances en materia del ordenamiento jurídico, mantiene latente un conflicto armado que afecta la estabilidad y las garantías que ofrece la ley a las víctimas. Situación apreciable al momento de la restitución de tierras, toda vez que, la presencia de grupos guerrilleros, representan un peligro para la integridad de aquellos que retornan a sus lugares legítimos.

Aunado a lo anterior, la Ley 1448 dispone, de acuerdo al informe Colombia: la ley de víctimas y de restitución de tierras realizado por Amnistía Internacional en el 2011, que se podría obstruir la posibilidad a aquellos que realizaran actos que hicieran alusión o se relacionaran con la restitución de las tierras a ejercer su derecho a la misma, estas regulaciones se pueden hacer efectivas respecto de cualquier persona que se haya manifestado así sea de manera no violenta, si se determina que por intermedio de su manifestación invadió, ocupó o uso una tierra sobre la cual no había decisión judicial previa. Lo anterior constituye una limitación a los Derechos de manera significativa, en especial cuando por condiciones externas el mismo Estado no reconoce garantías a las víctimas.

Esta ley, además creó el Centro Nacional de Memoria Histórica y con él, la generación de acciones para devolver a las víctimas su dignidad, su memoria, recuperar la verdad y crear las condiciones para las garantías de no repetición. Respecto de esta institución se identifica como "un establecimiento público del orden nacional, adscrito al Departamento para la Prosperidad Social, que tiene como objetivo recuperar y analizar de todo el material probatorio, relativo a 
las violaciones ocurridas con ocasión del conflicto armado interno colombiano" (Centro Nacional de Memoria Histórica). Frente al mandato de la Ley 975, el Centro Nacional de Memoria Histórica formuló el informe Basta ya: Colombia, memorias de guerra y dignidad, cuyo objetivo era elaborar un informe respecto de los orígenes y el desarrollo de los grupos armados en Colombia, de acuerdo al Centro, para dar cumplimiento a este trabajo la Institución analizó a las organizaciones ilegales, como resultado de los procesos sociales y políticos que ha afrontado el país a lo largo de su historia, y no solamente como una máquina generadora de violencia (Centro Nacional de Memoria Histórica, 2013).

Como resultado de un trabajo investigativo de más de seis años, en el año 2013 se publicó y compartió con la sociedad el informe citado, que expuso al país, en términos del Centro Nacional de Memoria Histórica, los alcances y los métodos de la guerra, el proceso evolutivo de los grupos ilegales, la repercusión de la violencia respecto de sus afectados, y sus memorias. Respecto de este informe se destaca su riqueza temática e investigativa, no obstante, se acota que no constituyó un informe de características integrales, como debe ser el de una comisión de la verdad, por lo tanto, no constituye un informe oficial y se aparta de ser una memoria formal.

Del informe resulta pertinente, hacer referencia al carácter de legitimidad que se les brindó a las víctimas, en atención a que fueron los victimarios, quienes por medio de sus relatos les dieron valor. Durante el periodo investigativo, tanto víctimas como victimarios, compartieron su testimonio, pero en el caso de los victimarios sus aportes fueron clave para el esclarecimiento de hechos y conducir a la verdad, es más sus versiones se adoptaron como sustento para dilucidar, si determinadas personas eran víctimas o no, propiciando un recrudecimiento del proceso e invirtiendo el valor de la palabra, que debió permanecer en título de las víctimas en razón al extenso número de violaciones de Derechos Humanos, que han tenido lugar en Colombia desde la década de los 50's a lo largo del territorio nacional.

En lo que corresponde a la verdad en el proceso con las FARC-EP, nació el sistema integral de verdad, justicia, reparación y no repetición. Dicho sistema se enfoca en la puesta en práctica de medidas de carácter restaurativo, con la finalidad de esclarecer la verdad respecto a los hechos que enmarcan el periodo de violencia en el país y contiene como característica su centralidad en las víctimas, así mismo para cumplir con el objetivo de verdad, se constituyó en él la Comisión para el Esclarecimiento de la Verdad, la Convivencia y la no Repetición (CEV). 
La creación de la Comisión para el Esclarecimiento de la Verdad, la Convivencia y la No repetición, surgió con el fin de ser un mecanismo imparcial y autónomo, sin tener un carácter judicial que entró en vigencia, una vez finiquitado y sancionado el Acuerdo de Paz. Según el escrito del 8 de marzo de 2020 del Centro Nacional de Memoria Histórica "En este nuevo escenario será posible aportar a la construcción y preservación de la memoria histórica y lograr un entendimiento amplio de las múltiples dimensiones de la verdad del conflicto, incluyendo la dimensión histórica, de tal forma que no sólo se satisfaga el derecho a la verdad, sino que también se contribuya a sentar las bases de la convivencia, la reconciliación, y la no repetición" (Pág. 1)

Frente a las características de la Comisión de la Verdad, esta institución será de carácter temporal y extrajudicial y estará conformada por miembros de múltiples sectores de la sociedad. No obstante, si bien es cierto que esté mecanismo no es judicial, los resultados deberán someterse a una verificación y no podrán ser usados con fines procesales ya que, su único fin es lograr el esclarecimiento y reconocimiento para que las víctimas conozcan lo sucedido en el conflicto interno.

Los objetivos de la Comisión para el Esclarecimiento de la Verdad, fueron determinados en el artículo 2 del Decreto Ley 588 de 2017 así:

1. Contribuir al esclarecimiento de lo ocurrido, de acuerdo con los elementos del Mandato y ofrecer una explicación amplia de la complejidad del conflicto, de tal forma que se promueva un entendimiento compartido en la sociedad, en especial de los aspectos menos conocidos del conflicto, como el impacto del conflicto en los niños, niñas y adolescentes y la violencia basada en género, entre otros.

2. Promover y contribuir al reconocimiento. Eso significa el reconocimiento de las víctimas como ciudadanos y ciudadanas que vieron sus derechos vulnerados y como sujetos políticos de importancia para la transformación del país; el reconocimiento voluntario de responsabilidades individuales y colectivas por parte de todos quienes de manera directa o indirecta participaron en el conflicto como una contribución a la verdad, a la justicia, a la reparación y a la no repetición; y en general el reconocimiento por parte de toda la sociedad de ese legado de violaciones e infracciones como algo que merece el rechazo de todos y que no se debe ni se puede repetir. 
3. Promover la convivencia en los territorios, en el entendido de que la convivencia no consiste en el simple compartir de un mismo espacio social y político, sino en la creación de un ambiente transformador que permita la resolución pacífica de los conflictos y la construcción de la más amplia cultura de respeto y tolerancia en democracia. Para ello promoverá un ambiente de diálogo y creará espacios en los que las víctimas se vean dignificadas, se hagan reconocimientos individuales y colectivos de responsabilidad, y en general se consoliden el respeto y la confianza ciudadana en el otro, la cooperación y la solidaridad, la justicia social, la igualdad de oportunidades entre hombres y mujeres, y una cultura democrática que cultive la tolerancia, promueva el buen vivir, y nos libre de la indiferencia frente a los problemas de los demás. La CEV deberá aportar a la construcción de una paz basada en la verdad, el conocimiento y reconocimiento de un pasado cruento que debe ser asumido para ser superado.

Como se observa esta comisión, tiene un papel preponderante e indispensable dentro del proceso de justicia transicional, toda vez que las Comisiones de la Verdad, desde un espectro pragmático, coinciden en tener como común denominador, buscar la verdad de todos los acontecimientos que dieron origen al conflicto y establecer las violaciones a los derechos humanos. No obstante, se conciben como un elemento fundamental de los procesos de justicia transicional, con el objeto de pasar a escenarios de paz. Según lo expuesto por el comisionado Alejandro Valencia (2018) en el portal web de la Comisión de la verdad, mediante este organismo, las víctimas y la sociedad en general pueden conocer, por medio de un relato sucinto, el qué y cómo ocurrieron los hechos, es decir, "Una comisión intenta dejarle una historia relativamente oficial, mucho más veraz de lo que ocurrió en relación con el conflicto armado y, sobre todo, un relato explicativo" (Alejandro Valencia, 2018).

Una última diferencia, se puede encontrar, frente a las penas a imponer. Por un lado, en la Ley de Justicia y Paz, se establecieron penas privativas de la libertad, en modalidad de penas alternativas, por un término no inferior a cinco (5) años y que no excediera los ocho (8) años, sanciones que debían ser impuesta por la sala competente del Tribunal Superior de Distrito, siempre y cuando el imputado haya cumplido los presupuestos procesales requeridos. Se puede indicar que a la fecha todos los integrantes de los grupos desmovilizados, que se beneficiaron con estas penas y que purgaron las mismas diferentes centros carcelarios del país, se encuentran en libertad. 
Con respecto a las sanciones impuestas en el Acuerdo de Paz, se implementaron sanciones propias, alternativas y ordinarias. Las primeras son para quienes reconozcan su responsabilidad y manifiesten plenamente la verdad y su pena será de cinco (5) a ocho (8) años en establecimiento no carcelario. La segunda para quienes reconozcan tardíamente su responsabilidad y verdad sobre los hechos con penas de cinco (5) a ocho (8) años, privativas de la libertad y por último, pero no menos importante, las sanciones ordinarias con penas previstas hasta veinte (20) de privación de la libertad. A la fecha, no se ha impuesto la primera sanción, para aquellos que se han postulado al Sistema Integral de Verdad, Justicia, Reparación y no Repetición.

\section{Conclusiones}

En el siglo XXI, la Ley 975 de 2005, se convierte en una norma pionera que permitió consolidar un mecanismo especial, para dirimir el conflicto armado interno, permitiendo que el Estado colombiano cumpliera con su deber constitucional de garantizar la paz. Por otro lado, posibilitó la desmovilización de grupos al margen de la ley, que durante muchos años sembraron el terror en el país. No obstante, desde su promulgación y trámite, esta ley ha generado una serie de contrastes jurídicos que conllevaron a ser demandada por inconstitucionalidad y a que la sociedad perdiera credibilidad en el proceso, sobre todo, por la desconfianza que se generó, pues se pone en entredicho la efectividad de la ley de Justicia y Paz, en cuanto a la reparación integral de las víctimas del conflicto armado, la verdad de lo ocurrido y sobre todo a la no repetición.

Frente al proceso de paz, suscrito con las Farc-EP, se puede advertir que este ha intentado abarcar, de manera integral todos los aspectos, que en un pasado fueron ignorados, cómo incorporación de la opinión de todos los grupos sociales, tener en cuenta todos los factores que influyeron en el desarrollo del conflicto interno, para que puedan ser intervenidos y de esa manera contribuir a la construcción de una paz estable y duradera.

Respecto de sus procedimientos, y en especial su temporalidad, aunado a la poca celeridad con la que se ha llevado a cabo cada etapa del proceso, puede ocurrir que muchos de los casos anteriores al primero de diciembre de 2016, queden sin ningún tipo de tratamiento judicial o extrajudicial, sin embargo, es loable reconocer los esfuerzos, para lograr las bases para reconstruir el tejido social que tantas veces fue maltrecho por los golpes de la violencia. 
En los procesos de Justicia Transicional, las Comisiones de la Verdad, son un instrumento indispensable para lograr los objetivos que esta se traza. Sin embargo, estos organismos deben actuar con independencia, es decir, sin que ninguna de las partes en el conflicto, intervengan en sus decisiones y sobre todo descalifiquen sus conclusiones.

Finalmente, en los dos procesos de Justicia Transicional que ha desarrollado Colombia en el siglo XXI, se pueden encontrar diferencias sustanciales en cuanto a las siguientes características:

- En cuanto a su nacimiento la Ley 975 de 2005, tuvo un origen legislativo, mientras que el Acuerdo de Paz presentó un trámite tortuoso desde un plebiscito hasta un Acto Legislativo para su aprobación final.

- Con respecto a los órganos de investigación y juzgamiento, la Ley de Justicia y Paz conformó unidades especiales en la Fiscalía General de la Nación para la investigación y la Jurisdicción Ordinaria se encargó del juicio y de la imposición de las sanciones de los desmovilizados, por el contrario, el Acuerdo de Paz estableció un procedimiento independiente de la jurisdicción ordinaria, creando el Sistema Integral de Verdad, Justicia, Reparación y no Repetición, integrado por: La Comisión para el esclarecimiento de la Verdad, la Convivencia y la no Repetición (CEV), La Unidad de Búsqueda de Personas dadas por Desaparecidas en el marco y en razón del Conflicto Armado (UBPD) y la Jurisdicción Especial para la Paz (JEP).

- Frente a la búsqueda de la verdad, en el desarrollo de la Ley 975 de 2005, nació el Centro Nacional de Memoria Histórica, dependiente del ejecutivo, sin embargo, no se constituyó como una comisión oficial y sus informes, en algunos casos fueron criticados por diferentes sectores de la sociedad. El Acuerdo de Paz, estableció como uno de los órganos necesarios para el desarrollo objetivo del proceso de Justicia Transicional una entidad independiente, la Comisión de la Verdad, con la misión de esclarecer lo sucedido en el conflicto.

- Finalmente se establece una diferencia, quizás de las más controvertidas por la sociedad y que corresponde a las sanciones a imponer a los exintegrantes de los grupos al margen de la ley pues, aunque las dos proponen penas menores que las de la justicia ordinaria, con la Ley 975 de 2005, las penas fueron privativas de la libertad, mientras que en el Acuerdo de Paz las penas, inicialmente no son privativas de la libertad. 


\section{Referencias}

Acosta, L. (2005). Conflicto colombiano, Historia y Contexto. Imprenta y publicaciones de las Fuerzas Militares. Bogotá.

Amnistía Internacional, (2011). Colombia: la ley de víctimas y de restitución de tierras. Recuperado de: https://repository.upb.edu.co/bitstream/handle/20.500.11912/1127/trabajo\%20de\% 20grado.pdf?sequence $=1$

Barbosa, F. (2017). ¿Justicia transicional o impunidad? La encrucijada de la paz en Colombia. Bogotá: Ediciones B.

Bushnell, D. (2008). Colombia una nación a pesar de sí misma. Editorial Planeta.

Cardona, A. (2011). El proceso penal especial de justicia y paz alcances y límites de un proceso penal concebido en clave transicional. Centro Internacional de Toledo para la Paz, 88384.

Centro Internacional Toledo para la Paz. (2011). El Proceso Penal Especial de Justicia y Paz Alcances y Límites de un Proceso Penal Concebido en Clave Transicional. (s.f.). Disponible

en: http://www.toledopax.org/sites/default/files/EL\%20PROCESO\%20PENAL\%20ESPECIA L\%20DE\%20JUSTICIA\%20Y\%20PAZ CITpax Observatorio.pdf

Centro Nacional de Memoria Histórica (2011). Ley de víctimas, nueve años de retos y Aprendizajes. Disponible en: https://centrodememoriahistorica.gov.co/ley-devictimas-nueve-anos-de-retos-y-aprendizajes/

Centro Nacional de Memoria Histórica. (2018). Justicia Balance de la Contribución del CNMH al esclarecimiento histórico. Disponible en: http://centrodememoriahistorica.gov.co/wpcontent/uploads/2020/01/BALANCE JUSTICIA.pdf

Centro Nacional de Memoria Histórica. (2019). Más de 13 mil desmovilizados de grupos paramilitares han contribuido a la verdad histórica. Disponible en: https://centrodememoriahistorica.gov.co/mas-de-13-mil-desmovilizados-de-gruposparamilitares-han-contribuido-a-la-verdad-historica/ 
Centro Nacional de Memoria Histórica (2020). Acuerdos de Paz. Disponible en: https://centrodememoriahistorica.gov.co/tag/acuerdos-de-paz/

Congreso de la República. Ley 975 de 2005, Por la cual se dictan disposiciones para la reincorporación de miembros de grupos armados organizados al margen de la ley, que contribuyan de manera efectiva a la consecución de la paz nacional y se dictan otras disposiciones para acuerdos humanitarios. Diario Oficial No. 45.980 de 25 de julio de 2005.

Congreso de la República. Acto legislativo No. 01 de 2012, Por medio del cual se establecen instrumentos jurídicos de justicia transicional en el marco del artículo 22 de la Constitución Política y se dictan otras disposiciones. Diario Oficial No. 48.508 de 31 de julio de 2012.

Congreso de la República. Acto legislativo No. 01 de 2016. Por medio del cual se establecen instrumentos jurídicos para facilitar y asegurar la implementación y el desarrollo normativo del acuerdo final para la terminación del conflicto y la construcción de una paz estable y duradera. Diario oficial No.49.927 de 7 de julio de 2016.

Congreso de la República. Ley Estatutaria 1806 de 2016, por medio de la cual se regula el plebiscito para la refrendación del acuerdo final para la terminación del conflicto y la construcción de una paz estable y duradera. 24 Agosto 2016, disponible en esta dirección: https://www.refworld.org.es/docid/5a95cd5c4.html [Accesado el 16 Septiembre 2021].

Cuervo, B \& otros, P. M. (2014). Origen y Fundamentos de la Justicia Transicional. Revista Vínculos, 38.

Departamento Administrativo de la Función Pública. Estructura del Proceso de Paz. https://www.funcionpublica.gov.co/documents/418537/1564007/EstructuraProceso PAZ.pdf/.

Gómez, B. (2007). Análisis jurídico y constitucional de la ley de justicia y paz. P.73-100.

Hernández, B. G. (2007). Análisis Jurídico y Constitucional de la ley de Justicia y Paz (Ley 975 de 2005). Revista Diálogos de Saberes, 28.

Hernández, E. (2015). Mediaciones en el conflicto armado colombiano. Revista Confines de Relaciones Internacionales y Ciencia Política, № 18 (2). 
Hernández, E. (2015). Empoderamiento Pacifista del actual proceso de paz en Colombia: 2012-2015. Revista de Paz y Conflictos Issn 1988-7221 | Vol. 8 | № 2 | 2015 | pp. 179202. Disponible en: file:///C:/Users/Usuario/Downloads/3118Texto\%20del\%20art\%C3\%ADculo-8674-1-10-20151220.pdf

Jurisdicción Especial para la Paz (2018). JEP. Disponible: https://www.jep.gov.co/JEP/Paginas/Jurisdiccion-Especial-para-la-Paz.aspx

Kalach, G. (2016). Las Comisiones de la Verdad en Colombia. Le droit à réparation des victimes de violations graves et massives des droits de l'homme en Colombie. Universitè Paris I Panthèon Sorbonne.

Mejía, C. Valencia, G. (2010). Ley de Justicia y Paz, un balance de su primer lustro. Universidad de Antioquia: disponible en: http://www.scielo.org.co/pdf/pece/n15/n15a3.pdf

Melo, O. (2017). Historia mínima de Colombia. Editorial Turner Madrid España.

Ministerio de Justicia y del Derecho. (2015). La ley de justicia y paz y el regreso a la vida civil: régimen de libertades, resocialización y reintegración de personas postulada. Bogotá D.C, Colombia.

Ocampo, J. Marín, A. (2015). La Ley de Justicia y Paz en Colombia de cara al Principio de Derecho. Universidad Libre de Colombia. Disponible en: https://repository.unilibre.edu.co/bitstream/handle/10901/9265/LEY\%20DE\%20JUSTI ClA\%20Y\%20PAZ\%20PDF.pdf?sequence=1\&isAllowed =y

Oficina del alto Comisionado para la Paz. (2018). De la refrendación al acuerdo del colón el plebiscito, el gran diálogo nacional, el acuerdo final y su refrendación. Tomo VII. Disponible en: https://www.jep.gov.co/Sala-de-Prensa/Documents/tomo-8-procesopaz-farc-refrendacion-plebiscito-.pdf

Presidencia de la República. Decreto 1391 del 30 de agosto de 2016. Por medio del cual se convoca a un plebiscito y se dictan otras disposiciones.

Salazar, (2017). Etapas de la construcción del Acuerdo Final de Paz. http://jepjusticiatransicional.net/etapas-de-la-construccion-del-acuerdo-general-depaz/.

Silva, E. (2013). Ley 1448 de 2011, una reflexión desde la ONU y organizaciones defensoras de Derechos Humanos. P. 42-83. 
Springer, N. (2012). Sobre la verdad en los tiempos del miedo. Del establecimiento de una Comisión de la Verdad en Colombia y los desafíos para la justicia restaurativa. Serie Pretextos. Bogotá: Universidad Externado de Colombia.

Uprimny, R. (2005). "La ley de Justicia y paz":¿procedimiento de verdad? Dejusticia. Disponible en: https://www.dejusticia.org/la-ley-de-justicia-y-paz-procedimiento-deverdad/

Valencia, A. (2018). Una mirada a las comisiones de la verdad en el mundo y a la de Colombia. Disponible en https://comisiondelaverdad.co/actualidad/noticias/una-mirada-a-lascomisiones-de-la-verdad-en-el-mundo-y-a-la-nuestra. 